\title{
PESSOAL
}

\section{Movimentação de Pessoal}

\author{
Tomás de Vilanova Monteiro Lopes
}

M

ovimentação de pessoal é o deslocamento de empregados, para dentro ou para fora da emprêsa. Conforme seus objetivos ou as causas que a determinam pode ela constituir um sintoma de vitalidade ou de enfraquecimento.

Há tipos de movimentação de pessoal que indicam que a emprêsa está rejuvenescendo os seus quadros ou redistribuindo sua mão-de-obra, para melhor ajustar-se às exigências de sua evolução. Há outros, porém, que revelam que ela está se mos trando incapaz de reter a seu serviço, ou nêle estabilizar, o elemento humano que lhe é indispensável; que está onerando os custos de sua produção com o vaivém de empregađos; que, enfim, se está debilitando pela perda progressiva de seus recursos de pessoal.

Os primeiros evitam o anquilosamento da emprêsa, soltam as rédeas para que ela possa acompanhar a marcha do progresso, permitem-lhe substituir as peças que o tempo desgastou ou tornou inúteis; os segundos, ao contrário, constituem fontes de exaurimento e de desperdicio, impedem que a emprêsa implemente suas bases de produção, incapacitam-na para a concorrência frente às outras emprêsas e podem conduzi-la ao desastre completo.

Há, assim, uma espécie de movimentação de pessoal positiva e outra negativa. Aquela é benéfica e esta, prejudicial à emprêsa.

A movimentação de pessoal positiva pode ser encarada:

a) como um processo de renovação; $e$

b) como um processo de ajustamento.

A movimentação de pessoal como processo de renovação. Seus instrumentos principais: aposentar tadoria, promoção, novas admissões.

A vida profissional tem um limite no tempo, além do qual a permanência do indivíduo em serviço torna-se nociva, socialmente porque obsta aos elementos novos a oportunidade de ingressarem 
ou de progredirem na profissão; funcionalmente porque mantém nos postos pessoas em quem a decadência física ou mental, ou a fôrça de hábitos consolidados por longos anos reduziram a adaptabilidade às novas condições de trabalho geradas pelo aperfeiçoamento das técnicas profissionais; econômicamente porque o aumento progressivo dos salários é correspondido por uma crescente redução da capacidade laborativa.

A delimitação de periodo de vida profissional tanto pode ser efeito do simples transcurso do tempo, como de outras causas (acidentes, doenças) que incapacitem o individuo para o trabalho.

São, pois, diversas as razões que criam para as emprêsas a necessidade de afastar de seus quadros os empregados que atingem o têrmo da vida profissional, ou de permitir que êles próprios tomem a iniciativa de promover o seu afastamento.

O processo através do qual as emprêsas afastam de seus quadros os empregados nas condições aqui indicadas denomina-se aposentadoria.

Num conceito mais preciso, aposentadoria é o processo mediante o qual o empregado qüe se incapacitou definitivamente para o trabalho ou atingiu o limite de permanência no emprêgo, ingressa, compulsória o11 voluntàriamente, no regime de inatividade remunerada, fazendo jús a um provento que é calculado de acôrdo com o tempo e o valor de suas contribuições para o fundo de previdência.

A importância que hoje se atribui aos aspectos sociais do problema faz com que a aposentadoria seja objeto de leis especiais que a retiram do terreno da livre convenção entre empregadores e empregados, e a submetem a um conjunto de preceitos gerais e uniformes. Para as emprêsas brasileiras êsses preceitos são os estabelecidos pela Lei Orgânica da Previdência Social (Lei $n^{\circ} 3.807$, de 26-8-60) que prevê as seguintes modalidades de aposentadoria:

13) Aposentadoria por invalidez (arts. 27 a 29).

2:) Aposentadoria por velhice (art. 30).

3a) Aposentadoria especial (art. 31); e

4a) Aposentadoria por tempo de serviço (art. 32).

A aposentadoria por invalidez - Para a concessão da aposentadoria por invalidez dois requisitos são indispensáveis:

a) incapacidade do empregado para o exercício do trabalho que vinha desempenhando; $e$

b) impossibilidade de seu aproveitamento noutra atividade compativel com as suas aptidões. (Tais requisitos apurar-se-ão 
através de exames, a cargo da instituição de previdência social, exceto nos casos de doença sujeita a reclusão compulsória, hipótese em que o aludido exame será substituído pela comunicação ou atestado da autoridade sanitária competente).

$\mathrm{Na}$ aposentadoria por invalidez o provento é o equivalente a $70 \%$ (setenta por cento) do salário de benefício ("média dos salários sôbre os quais o segurado haja realizado as últimas 12 (doze) contribuições mensais"), acrescido de mais $1 \%$ (um por cento) do referido salário para cada grupo de doze contribuições mensais, até a máximo de $30 \%$ (trinta por cento).

O aposentado por invalidez fica sujeito a novos exames, para contrôle das causas que determinaram seu afastamento do serviço e, desde que seja considerado inteiramente apto para o trabalho, a aposentadoria será cancelada; se. porém, a recuperação fôr parcial, reconhecendo-se ao aposentado capacidade para exercer trabalho diverso do que habitualmente exercia, o provento da aposentadoria será mantido, integralmente, durante seis meses; dai em diante, por mais seis meses, sofrerá uma redução de $50 \%$ (cinqüenta por cento); em seguida ficará reduzido $1 / 3$, ainda pelo prazo de seis meses, findo o qual a aposentadoria será cancelada.

Consolidação das Leis do Trabalho completa os preceitos acima, dispondo:

"Art. 475. O empregado que fôr aposentado por invalidez terá suspenso o seu contrato de trabalho durante o prazo fixado pelas leis de previdência social para efetivação do benefício.

$\S 1$ Recuperando o empregado a capacidade de trabalho e sendo a aposentadoria cancelada, ser-lhe-á assegurado o direito à função que ocupava ao tempo da aposentadoria, facultado, porém, ao empregador o direito de indenizá-lo por rescisão do contrato de trabalho, nos têrmos dos arts. 477 e 478 .

$\S 22^{\circ}$ Se o empregador houver admitido substituto para o aposentado, poderá rescindir, com êste, o respectivo contrato de trabalho, sem indenização, desde que tenha havido ciência inequivoca da interinidade ao ser celebrado o contrato.

A Aposentadoria por velhice - Duas são as modalidades de aposentadoria por velhice: a voluntária e a compulsória. A primeira depende de solicitação do interessado, devendo êste provar:

a) que conta, no mínimo, 65 anos de idade, quando do sexo masculino, ou 60 , quando do sexo feminino; e

b) que realizou, no minimo, sessenta contribuições mensais para o fundo de previdência. 
A segunda depende de requerimento do empregador, sendo admissivel quando o empregado houver completado setenta anos de idade (sexo masculino) ou sessenta e cinco anos (sexo feminino).

No caso de aposentadoria compulsória o empregado receberá além do provento calculado na mesma forma estabelecida para a aposentadoria por invalidez, metade da indenização a que a leı obriga o empregador pela rescisão, sem justa causa, do contrato de trabalho.

Parece-nos que o legislador não estêve bem inspirado quando impôs essa obrigação ao empregador, pois que com ela o propósito de se conceder ao empregado uma situação especial foi inteiramente frustrada, com prejuizo não só das partes vinculadas ao contrato de trabalho, como da própria coletividade. E' que, em tais casos, a indenização atinge a cifras elevadas e nem sempre o empregador está em condições de atender ao encargo, ou julga de sua conveniência fazê-lo, preferindo deixar que o empregado senil continue no trabalho para o qual já não dispõe das condições físicas necessárias. Com isso são adiadas as oportunidades que deveriam ser abertas aos novos profissionais; não se garantem ao velho empregado as regalias com as quais se pensou beneficiá-lo; nem se assegura o preenchimento dos postos de trabalho pelas pessoas mais aptas a ocupá-los, como o interêsse social reclama.

A aposentadoria especial - A aposentadoria especial, ao contrário das duas modalidades anteriormente apresentadas, não se fundamenta nem na incapacidade para o trabalho nem na senilidade, mas no direito ao repouso que se deve reconhecer ao indivíduo que trabalhou durante muitos anos, sobretudo em se tratando de serviços que pela sua natureza envolvem riscos, desconfôrto ou perigos acima do comum. Para que ela se efetive a lei impõe três condições:

a) que o empregado conte, no minimo 50 anos de idade;

b) que tenha contribuido para o fundo de previdência, no minimo, durante 15 anos e;

c) que tenha trabalhado por periodo não inferior a 25 anos, salvo em se tratando de atividades penosas, insalubres ou perigosas, casos em que êsse período poderá ser reduzido para 20 ou para 15 anos. O provento do aposentádo será calculado pela mesma forma que indicamos ao tratar da aposentadoria por invalidez.

A aposentadoria por tempo de serviço - Ao indivíduo que passou a maior parte de sua vida no trabalho, geralmente com poucas oportunidades de repouso e de recreação, deve ser as- 
segurado o direito a um fim de existência mais descansado. Esse o fundamento da aposentadoria por tempo de serviço. Para que ela seja concedida a única exigência legal é a de que o empregado, conte no minimo, trinta anos de serviço (para receber $80 \%$ do salário). Pode, entretanto, o empregado preferir continuar na atividade, hipótese em que fará jús a um abono mensal de $25 \%$ do salário benefício, a ser pago pela instituição de previdência social a que estiver filiado e, ao aposentar-se, seu provento será acrescido de mais $4 \%$ do salário benefício para cada grupo de doze contribuições mensais, até o máximo de $20 \%$.

\section{A PROMOÇÃO}

As aposentadorias abrem vagas nos quadros de pessoal da emprêsa e como tais vagas, via de regra, dizem respeito a postos intermediários ou finais na escala da hierarquia e dos salários sua ocorrência da ensejo à promoção ou ao acesso de empregados.

$O$ instituto da promoção ainda não foi regulamentado pela legislação trabalhista que a êle se refere (C.L.T. art. 460) para dizer que o principio de igual salário para trabalho de igual valor nâo prevalecerá quando os empregados estiverem organizados em quadro de carreira, devendo, nesta hipótese haver promoções pelos critérios de antiquidade e de merecimento, alternadamente. Merece louvores a cautela com que o legislador encarou a matéria, uma vez que a generalização do instituto seria, sob quase todos os aspectos, de manifesta inconveniência.

Promoção é o acesso do empregado a cargo de melhor remuneração. Podemos entendê-la também como sendo o acesso do empregado a cargo de melhor remuneração e de atribuições mais complexas, pelo seu nivel de dificuldade e de responsabilidade. A êsses dois conceitos correspondem respectivamente, dois tipos distintos de promoção: a horizontal e a vertical. Quando consideramos que o objetivo da promoção não deve ser apenas propiciar melhor salário ao empregado, mas também possibilitar o seu aproveitamento em funções que reclamam um grau mais elevado de capacidade funcional, compreendemos que a promoção do tipo vertical é a que mais se recomenda. O que lhe tem restringido a adoção é o fato de ela exigir certas condições que envolvem problemas técnicos de difícil solução, sobretudo nos serviços públicos e nas grandes emprêsas. Não será viável a promoção vertical, sem que antes tenhamos:

a) um hierarquização funcional;

b) a definição das atribuições dos cargos, nos diferentes niveis hierarquizados: 
c) um programa de treinamento e de formação para os postos mais importantes, ou na pior das hipóteses, a adaptação dos sistemas cồmuns de ensino às necessidades, exigências e objetivos da promoção; $e$

d) um plano de pagamento diferencial, para os niveis que forem estabelecidos.

São dois os critérios de promoção: o de antigurdade e o de merecimento. Este último apresenta diversas variantes, tantas quantas forem as maneiras de conceber a eficiência ou merecimento do empregado e, portanto. de aferi-los. O critério de merecimento é àrduamente defendido em nome do estímulo que às organizações cabe dispensar aos seus servidores mais enérgicos, ambiciosos e capazes, pois é dêles que elas recebem os melhores influxos de vitalidade e de progresso. Preteri-los seria não apenas ato de injustiça, como também demonstração de incapacidade administrativa já que não há fator que abale tão profundamente a moral de uma organização como a preterição do mérito, na hora de distribuir as recompensas. O critério de merecimento nem por isso está a salvo de restrições, contra êle se invoca o perigo da ascenção aos postos de maior responsabilidade de indivíduos sem o amadurecimento necessário, dos "carreiristas" que, sob o disfarce da eficiência, cuidam mais do seu próprio sucesso do que dos interêsses da organização a que pertencem. Ademais disso, acrescenta-se, a aferição do merecimento é muito subjetiva e na prática produz grandes injustiças, já que depender da apreciação pessoal de chefes de feitios psicológicos diferentes e se processa sob circunstâncias as mais variadas, não assegurando, assim, uma base de comparação capaz de permitir um julgamento fiel do valor funcional dos candidatos à promoção. No debate dos critérios da promoção é pôsto em destaque o reconhecimento que as organizações devem aos seus servidores mais antigos, àqueles que a ajudaram, com seu devotamento e lealdade, a superar as incertezas do tempo, e lhe acresceram as possibilidades de êxito com a experiênca e o amadurecimento que só a longo tirocinio profissional pode produzir. $E^{\prime}$ verdade que a permanência por largo tempo numa organização recomenda o empregado sob muitos aspectos, e imprime um caráter de excessiva severidade à idéia de obrigá-lo a competir pelos melhores postos em igualdade de condições com os seus colegas mais jovens, beneficiários de uma aprendizagem mais recente de melhores possibilidades educacionais e até mesmo da experiência dos que encaneceram no trabalho. Tudo isso é verdade, mas não é menos exato que a certeza de ser promovido por antiguidade pode levar o empregado a renunciar ao esfôrço, pelo aperfeiçoamento de sua atuação funcional. As razões que militam a favor e contra cada um dos dois cri- 
térios de promoção, como acabamos de ver, são igualmente respeitáveis. Por isso mesmo. na prática. os critérios de antiguidade e de merecimento aparecem quase sempre associados dentro de um mesmo sistema de promoção, em pé de igualdade, ou com certo predominio de um sôbre o outro.

Para a implantação de um sistema de promoções é necessârio que o empregador estabeleça, prèviamente:

a) quais os requisitos que o empregado deverá preencher, no que se refere:

1) ao tempo de serviço (mesmo nas promoções por merecimento exige-se que o empregado conte certo tempo de exercício no cargo que ocupa, a fim de que a promoção não venha a verificar-se dentro do periodo de estágio probatório, nem deixe de haver entre duas promoções sucessivas um lapso de tempo razoável, para adaptação do empregado ao cargo a que ascendeu pela primeira promoção).

$2^{\circ}$ ) à conduta funcional (mesmo nas promoções por anti guidade deve o empregado satisfazer a certas condições minimas de conduta funcional, como por exemplo, não ter sofrido, dentro de certo período de tempo imediatamente anterior à época da promoção, pena disciplinar grave, nem faltado ao serviço, injustificadamente, durante um número estipulado de dias de trabalho).

b) quais os critérios a serem obedecidos na apuração dos requisitos, relativamente:

18) ao tempo de serviço (como deve ser contado o tempo de serviço? em dias? semanas? meses? anos?; que descontos sofrerá o empregado em seu tempo de serviço pelo não comparecimento ao trabalho, pelas entradas tardias ou pelas saidas ante-
cipadas?).

2:) à conduta funcional (quais os elementos que devem ser considerados e qual o valor a ser atribuido a cada um? a quem caberá a competência para julgar a conduta funcional do empregado? quais os descontos que poderá o empregado sofrer no seu indice de conduta funcional pelas faltas que houver cometido?). peito:

c) quais as normas a serem observadas, no que diz res-

$\left.1^{a}\right)$ à época das promoções (serão as promoçõcs realizadas em qualquer época, ou obedecerão a um calendário especial?).

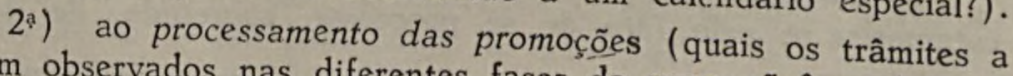
serem observados nas diferentes fases da promoção? qual a se-. qüência dos atos? quais os formulários ou modelos de expediente 
a serem usados? como serão calculados os indices de tempo de serviço e de conduta funcional? quais as fórmulas para classifi cação dos empregados? quais os critérios de preferência, em caso de empate? como serão acolhidas e julgadas as reclamações?).

\section{AS NOVAS ADMISSÕES}

As aposentadorias abrem vagas para as promoções; e estas, por sua vez, criam oportunidade de admissão de novos empregados. Àquelas propiciam o rejuvenescimento do pessoal nos postos mais elevados; estas fazem o mesmo em relação aos postos iniciais.

Ao ensejo das novas admissões deve a emprêsa reexaminar seus processos de recrutamento e seleção, a fim de melhor adaptá-los às suas necessidades, bem como aproveitar a ocasião, para introduzir nas suas rotinas e regulamentos as modificações que, por ventura, se tenham mostrado necessárias.

A parte êsse trabalho de revisão, que as novas admissões permitem seja feito sem ferir situações já constituídas, o preenchimento das vagas abertas nos postos iniciais obedece a mesma sistemática que tem no recrutamento, na seleção e na colocação, funções que tratamos em trabalhos anteriores, $\left({ }^{*}\right)$ suas peças essenciais. A simples existência da vaga não implica por si só em nova admissão, pois que, em muitos casos, pode ensejar a extinção de um cargo desnecessário.

O Chefe do órgão interessado ao pedir a admissão de um nôvo empregado deve ministrar ao Serviço de Pessoal tôdas as informações relativas aos tipos de trabalho próprio do cargo a ser preenchido, às condições sob as quais são êles executados, e às características pessoais que exigem, e não se limitar a soli citar, vagamente, "mais um funcionário para preencher a vaga
resultante da promoção de Fulano".

De posse do pedido de requisição o Serviço de Pessoal tomará as providências que lhe couberem para o recrutamento, seleção e colocação do nôvo empregado.

A movimentação de pessoal como processo de ajustamento. Seus instrumentos principais: a trans. ferência e a readaptação.

A movimentação de pessoal como processo de renovação caracteriza-se pelo fato de se processar, sobretudo, de dentro

(*) Veja-se "Problemas de Pessoal da Emprêsa Moderna" - 2" edição
Fundação Getúlio Vargas - Rio -1965. 
para fora ou de fora para dentro da emprêsa, acarretando, quase sempre, redução ou aumento do volume da mão-de-obra.

Certos problemas suscitados pela evolução da emprêsa, podem, porém, ser solucionados mediante a simples movimentação interna do pessoal. Em tais casos não há necessidade de se recorrer nem a desligamentos nem a novas admissões, bastando, apenas que se proceda à redistribuição da mão-de-obra disponível, para melhor ajustá-la às transformações surgidas na vida da emprêsa. A movimentação de pessoal que se opera em tais condições constitui um processo de ajustamento, por isso que implica na simples acomodação do quadro de empregados às situaçöes novas, sem alterar-lhe o efetivo que permanece o mesmo.

A regularidade da vida das emprêsas exige que as atribuições de seu pessoal apresentem certa fixidez, que cada servidor fique vinculado, de modo permanente, a determinado cargo ou função. Uma emprêsa cujos empregados estivessem a cada momento mudando de atribuições não conseguiria manter-se, por falta dos elementos essenciais de ordem interna. Mas as emprêsas evoluem e, no curso de sua existência, se defrontam com a necessidade de dispor do seu pessoal, de proceder a uma redis. tribuição das respectivas atribuições, de sorte que os servidores excedentes em determinadas atividades possam ser aproveitados noutras. Por sua vez o empregado, no curso de sua vida funcional, pode interessar-se por outros campos de atividades ou adquirir, dentro da própria emprêsa ou mesmo fora dela, um treinamento especial para novas funções. Também nestas hipóteses, seja para dar ao empregado oportunidade de exercer os seus pendores, seja para aproveitá-lo em função onde êle possa dar maior rendimento, a emprêsa não prescinde da faculdade de conferir-lhe atribuições novas. As duas tendências opostas, a primeira traduzida na necessidade de fixidez das atribuições visando a criar condições para a especialização e a segunda inspirada nas exigências da adaptação da emprêsa às condições de sua evolução, e da do empregado às modificações dos seus interêsses e aptidões funcionais, condicionam a movimentação de pessoal como processo de ajustamento. Por outro lado a diversidade dos motivos que conduzem a essa movimentação dá lugar a várias hipóteses, as quais são atendidas pelas diferentes formas de transferência, ou pela readaptação.

Transferência é ato em virtude do qual o empregado, a pedido seu ou "ex-offício" no interêsse da administração passa de um cargo ou função para outro de igual padrão de vencimento.

Distingue-se nitidamente dos demais tipos de provimento dos cargos, pois não é uma forma de ingresso no serviço como a 
nomeação; não constitui um acesso a classe superior como a prumoção; não implica o desligamento do funcionário e o seu retôrno ao serviço, como a readmissão e a reintegração; nem pressupõe, como o aproveitamento e a reversão, a inatividade do funcionário.

As considerações que expendemos antes deixam entrever que, em muitos casos, a transferência do funcionário é medida que se impõe para atender aos interêsses da organização. Esta, por isso mesmo, deve ter a faculdade de torná-la efetiva, por sua própria iniciativa, independentemente de provocação; outras vêzes, porém, a transferência é medida que interessa ao funcionário, sendo natural que a êste se reconheça dentro de certas condições, a faculdade de socilitá-la. Quando proveniente do exercício da faculdade reconhecida à administração, a transferência se diz "ex-officio", quando oriunda da faculdade deferida ao empregado, se diz a pedido. A transferência "ex offício", sem que haja anuência do empregado ou extinção do estabelecimento em que o mesmo trabalhar, só poderá ser feita para localidade diversa da fixada pelo contrato de trabalho quando ocorrer ne-
cessidade do serviço; mas neste caso o empregador fica obrigado a pagar, além das despesas resultantes da transferência um adicional nunca inferior a $25 \%$ do salário do empregado, enquanto êste permanecer fora de sua sede contratual. (C.L.T., arti-
gos 469 e 470)

A transferência a pedido depende da iniciativa do funcionário, podendo a emprêsa concedê-la ou não. Sempre que não preser concedida. Seu indeferimento pode criar situações prejudiciais à tranqüilidade da convivência no ambiente de trabalho, e pode mesmo importar numa espécie de castigo ao funcionário que, por motivos justos, deseja ser transferido. Não se conclua dai, porém, que a transferência a pedido deva ser concedida indiscriminadamente, o que propiciaria o "borboleteamento" dos empregados inadaptáveis, ou permitiria que os casos disciplinares, ao invés de serem solucionados desde logo, procurassem evadir-se ou fôssem passando de mão num verdadeiro jôgo de empurra, dando ensejo
a que o tempo trabalhasse a favor do mau empregado.

A transferência, contorme vimos acentuando, deve suborciinar-se aos interêsses da organização e ninguém melhor para interpretar êsses interêsses do que o chefe do serviço ao qual peringressar. Pode acontecer quele no qual o empregado pretende de prescindir da collecer que o primeiro não esteja em condições endê-lo com uma tranoração do funcionário e neste caso, surpreendê-lo com uma transferência prejudicial ao bom andamento to 
serviço seria grave êrro, isso sem contar com o desprestigio que da omissão da consulta prévia resultaria para o Chefe. Por outro lado, poderia o Chefe do serviço para o qual se desejasse fazer a transferência ter motivos respeitáveis para obstá-la e, então, não seria aconselhável impor-lhe uma situação contra a qual êle se opusesse com fundamentos legitimos.

Observe-se, ademais, que nas emprêsas cujos cargos sao organizados em sistema de carreiras a promoção, não raro, interfere $\mathrm{c}(\mathrm{m}$ o problema da promoção, uma vez que pode determina: o desrparecimento de vagas destinadas ao acesso dos antigos empregados pertencentes à carre:ra na qual o transferendo iria ingressar. Ante a impossibilidade de eliminar de todo êsse inconveniente, e não podendo a administração excusar-se de as. segurar ao sistema de promoções o mínimo de oportunidade indispensável ao seu regular funcionamento, tem-se adotado a prática de só permitir que seja preenchida por transferência uma parte das vagas verificadas nas classes intermediárias e finais dns carreiras.

Há uma espécie de transferência a que se dá o nome de readaptação, a qual visa ao aproveitamento do funcionário, que se incapacitou total ou parcialmente para as funções que vinha exercendo, noutra função compativel com as suas aptidões. Através da readaptação podem as emprêsas atender a situações oriundas de acidentes, moléstias profissionais e outras causas, abrindo aos seus empregados novas oportunidades de trabalho, antes de recorrerem à demissão ou à aposentadoria .

Outrora a readaptação era limitada aos casos de incapacidade física, dai ter sido considerada, por muito tempo, como um problema de medicina do trabalho. Hoje, a readaptação por motivos psicológicos (v.g. aversões, fobias etc.) e organizacionais (v.g. desvio de função) é largamente usada.

Nossa legislação trabalhista, entretanto, e a nosso ver acertadamente, $\left({ }^{*}\right)$ ainda não evoluiu até êsse ponto. Seu conceito de readaptação não é dos mais amplos, como se pode ver dos seguintes dispositivos da Lei de Acidentes do Trabalho (Decretolei $n^{\circ}$ 7.036, de 10-11-44).

“Art. 90. A readaptação profissional que é devida a todo incapacitado do trabalho, tem por objetivo restituir-lhe, no todo

(*) Para se compreender essa observação basta que se conside:c o que tem ocorrido no Serviço Público com a prática da readaptação por desvio de função. 
ou em parte a capacidade na primitiva profissão ou em outra compativel com a suas novas condições físicas.

"Art. 91. A readaptação profissional dos incapacitados para o trabalho será realizada atravês de serviços de readaptação profissional que tuncionarão na forma determinada em regulamento, e efetuar-se-ão não só mediante a prática da fisioterapia, da cirurgia ortopédica e reparadora, mas ainda do ensino conveniente em escolas profissionais especiais.

"Art. 92. O Estado determinará o regime sob o qual deverão funcionar as escolas de que trata 0 artigo anterior, assin como as condições para a prática do ensino correspondente.

$\S 1^{\circ}$ Criadas as escolas profissionais especiais, regular -se-á a admissão dos readaptados em funções que possam exercer com
eficiência.

$\S 2^{\circ}$ Em regulamento serão fixadas quais as funçoes que devam ser exercidas, preferencialmente, por incapacitados rea-
daptados.

"Art. 93. Em nenhum caso, a readaptação profissional ob tida pelo acidentado será motivo de revisão do acôrdo ou sentença que houver fixado a indenização pelo acidente do trabalho.

$\S 1$ \% $O$ incapacitado que no periodo de readaptação perceber remuneraçâo pelos serviços executados nas escolas profissionais especiais, não terá suspenso o pagamento de aposentadoria concedida por instituiçäo de previdência social em cujo gôzo se
achar.

$\S 22^{\circ}$ A acumulação da remuneração percebida em suas novas funções pelo incapacitado readaptado com a importância de aposentadoria em cujo gôzo se encontrar é permitida, até im portância correspondente ao dôbro do salärio minimo local, reduzindo-se o quanto da aposentadoria, quando a soma das duas
exceder a êsse limite". saber:

$\mathrm{Na}$ prática da readaptação há três etapas fundamentais

1:) Verificação dos motivos em que se fundamenta a proposta de readaptação. (Conforme a natureza dos motivos apresentados essa verificação far-se-á através de exame médico, pro-
vas psicológicas etc.).

2: Audiência dos Chefes de Serviço interessados, para que veniências dos órgãos sob sua responsabilidade. 
3a) Apuração da posse, pelo readaptando das condições de capacidade exigidas pelo cargo no qual se tem em vista readaptá-lo. (Essas condições podem dizer respeito a conhecimentos, experiência profissional, aptidões especiais, etc., e em cada caso serão utilizados os meios de investigação apropriados. Muitas vêzes, comprovada a ausência de tais condições, pode-se submeter o readaptando a um periodo de treinamento prévio, a fim de prepará-lo para a readaptação).

As etapas aqui mencionadas se dizem fundamentais por qut se destinam à apuraçäo de requisitos que devem ocorrer conjuntamente, para que a readaptação se concretize. A falta de qualquer dêles constitui, por si só, um impedimento decisivo, já que não se compreende possa haver readaptação sem fundamento legítimo, ou em oposição aos interêsses do serviço, ou, ainda, quando o readaptando não tenha capacidade para o exercício de nôvo cargo.

A efetivação da transferência e da readaptação de empregados deve cercar-se de muita cautela, porque do contrário poderá produzir certos inconvenientes, tais como:

19) Rivalidade entre os Chefes de Serviço, motivada pelo aliciamento de empregados;

2.) Desorganização de equipes de trabalhos já constituidos, pelos desfalques aos quais a transferência pode submetê-las;

32) Desprestígio da Chefia, quando esta não é ouvida ou é contrariada nas transferências, sobretudo se estas envolvem problemas disciplinares.

4\%, Desajustamento do empregado, pela falta de aptidão ou capacidade para o exercício do nôvo cargo.

5\%) Desequilibrio na distribuição dos empregados pelos diferentes órgãos da emprêsa, devido à competição que se estabelece em tôrno dos cargos que oferecem maiores comodidades ou melhores perspectivas.

6?) Facilidade de evasão dos casos disciplinares e incentivo à insubordinação.

7 ) Perda ou inaproveitamento da experiência adquirida pelo empregado no exercício do cargo do qual se tem em vista transferi-lo.

89) Dificuldades dt ordem administrativa para a execução daquelas atividades cujo planejamento se baseou na existência de um quantitativo de pessoal determinado. 
As transferências e readaptações que conduzem aos inconvenientes acima enumerados se dizem irregulares e ensejam a movimentação de pessoal negativa.

A movimentação de pessoal como sintoma de deficiência da administração.

O oposto da movimentação de pessoal é a estabilidade da mão-de-obra, devendo esta ser entendida não como estagnação $c$ imobilismo, mas como um estado de evolução em que se verificam perdas e acréscimos no efetivo da mão-de-obra, umas e outros, porém, refletindo transformações normais num organismo vivo, como é tôda emprêsa. A estabilidade da mão-de-obra, portanto, não há de ser absoluta, mas relativa. Desde que as causas da movimentação de pessoal constituam, pela sua natureza, uma exigência daquela evolução não haverá motivos para estranheza. Êstes só passarão a existir no momento em que a estabilidade da mão-de-obra é quebrada por fatôres que longe de representarem imposições da evolução normal da emprêsa constituem obstáculos a essa evolução pelo que traduzem de desperdicio de recursos humanos e valôres organizacionais.

Por assim conceber o fenômeno foi que, linhas atrás, distinguimos e conceituamos duas formas de movimentação de pessoal: a positiva e a negativa. Da primeira já nos ocupamos, mostrando como ela se configura quer como processo de renovação, quer como processo de ajustamento de mão-de-obra.

Quando examinamos mais atentamente a movimentação de pessoal negativa verificamos que sob a aparência por vêzes enganadora das cousas o que há de predominante é a falta de integração da mão-de-obra à emprêsa. Nesse particular duas
situações são possíveis:

a) o empregado não se integrou à emprêsa; porque não tinha condições para isso, ou

b) a emprêsa não proporcionou ao empregado as condições necessárias para que êle a ela se integrasse.

A primeira hipótese envolve a acusação de que $\curvearrowright$ sistema de recrutamento e seleção deixou de preencher os seus reais objetivos, que êle não soube colocar a serviço da emprêsa o elemento humano com as qualificações adequadas; a segunda abrangeu um conjunto de fatôres bem mais complexos e diversificados. Para usar uma expressão que, embora um tanto vaga e genérica, abranja todos êles, poderemos falar em "administração de pessoal
deficiente". 
A administração de pessoal deficiente resulta de um conjunto de causas e efeitos que o quadro abaixo procura sintetizar, considerando as situações mais comuns:

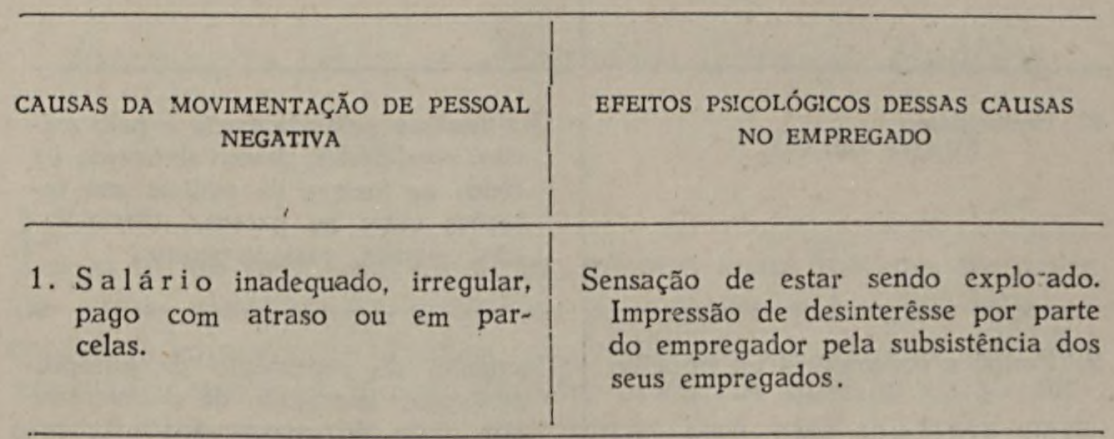

2. Ausência de oportunidades de prog:esso.

Sensação da inutilidade do esfôrço para bem servir, e do mérito demonstrado no trabalho.

3. Chefia autoritária.

Sentimento de revolta contra o empregado:, dissimulação, mêdo, angústia, frustração.

4. Insegurança no emprêgo.

Falta de confiança no empregador, ansiedade, exacerbação do mecanismo de autodefesa.

5. Indefinição dos direitos e obrigações.

Sentimento de dúvida e incerteza, decepções, impressão de estar sendo injustiçado, ou exposto a ciladas.

6. Deficiência da seleção inicial.

Inadaptabilidade ao trabalho, por falta de conhecimento ou de aptidões, predisposição a acidentes, frustração, angústia.

7. Ausência de treinamento.

Sensação de estar sendo abandonado, desassistido, e tolhido em suas aspirações de progredir no emprêgo. 


\begin{tabular}{|c|c|}
\hline $\begin{array}{c}\text { CAUSAS DA MOVIMENTAÇÃO DE PESSOAL } \\
\text { NEGATIVA }\end{array}$ & $\begin{array}{c}\text { EFEITOS PSICOLÓGICOS DESSAS CAUSAS } \\
\text { NO EMPREGADO }\end{array}$ \\
\hline 8. Favoritismo. & $\begin{array}{l}\text { Desinterêsse pela eficiência e pelo mé- } \\
\text { rito, rivalidades, desenvolvimento de } \\
\text { tôdas as formas da malicia nas re- } \\
\text { lações entre as pessoas, dissimula- } \\
\text { ção, revolta, ressentimentos. }\end{array}$ \\
\hline
\end{tabular}

9. Perigo e desconfôrto no trabalho.

Excitação do sentimento de autopreservação. Impressão de desinterêsse por parte do empregador pela segurança e bem estar dos seus empregados.

10. Sistema de dois pesos e duas

Sentimento de dúvida, perplexidade, medidas. falta de cónfiança no senso de justiça e na imparcialidade do empregador; decepções, ressentimentos.

As situações que o quadro acima configura podem levar o empregado, conforme a personalidade dêste ou as circunstâncias de cada caso, a pedir dispensa do emprêgo, ou a abandoná-lo, simplesmente, para ir buscar alhures a realização de suas aspirações. Mas também podem levá-lo a assumir dentro da emprêsa uma atitude de frustração, com as conseqüências nocivas que daí poderão resultar. Os ônus da administração de pessoal deficiente não recaem, apenas, sôbre a emprêsa; o empregado suporta-os, igualmente, já que se desgasta na angústia e na irrita.. ção que o ambiente de trabalho lhe causa, adquire hábitos que lhe serão prejudiciais mais tarde e, na maioria das vêzes, acaba se deixando possuir de um sentimento generalizado de hostili dade em relação aos empregadores, predispondo-se, assim, a novos insucessos em sua carreira. Para ambas as parte, portanto, o menor dos males ainda é o afastamento do servidor desajustado e tal afastamento deve processar-se o mais cedo possivel. 